\title{
Increased prevalence of some birth defects in Korea, 2009-2010
}

Dirga Kumar Lamichhane ${ }^{1}$, Jong-Han Leem ${ }^{1,2^{*}}$, Myungsook Park1, Jung Ae Kim¹, Hwan Cheol Kim², Jin Hee Kim ${ }^{3}$ and Yun-Chul Hong ${ }^{4}$

\begin{abstract}
Background: Birth defects are a leading cause of neonatal and infant mortality, and several studies have indicated an increase in the prevalence of birth defects; more recent investigations have suggested that the trends of some defects are increasing in rapidly industrialized areas. This study estimates the prevalence rate and types of birth defects in Korea.

Methods: This study used medical insurance benefit data of 403,250 infants aged less than one year from the National Health Insurance Corporation from seven metropolitan areas in Korea for 2009 and 2010.

Results: The prevalence rate of birth defects was 548.3 per 10,000 births (95 \% Cl: 541.1-555.6), 306.8 among boys and 241.5 among girls. Anomalies of the circulatory system (particularly septal defects) were the most common (180.8 per 10,000), followed by defects of the genitourinary tract (130.1 per 10,000) (particularly obstructive genitourinary and undescended testis), musculoskeletal system (105.7 per 10,000), digestive system (24.7 per 10,000), and central nervous system (15.6 per 10,000).

Conclusions: Relatively higher rates of some birth defects were found in the metropolitan areas. The high differences of birth prevalences for septal heart defects and undescended testis are probably due in part to progress in clinical management and more frequent prenatal diagnosis. Environmental exposure might play a critical role in the development of some birth defects. In attempting to describe the prevalence and spatio-temporal variations of birth defects in Korea, establishment of a registry system of birth defects and environmental surveillance are needed.
\end{abstract}

Keywords: Birth defects, Prevalence, Korea

\section{Background}

The prevalence of birth defects has continued to increase and has also led to a significant proportion of infant and childhood mortality, whereas the infectious causes are decreasing due to the extensive and successful use of prevention and control programs [1, 2]. Approximately $3 \%$ of 134 million annual births worldwide are associated with a major structural disorder [3]. The prevalence of birth defects varies among countries and regions. For more than two decades in the United States, birth defects have been the major cause of infant

\footnotetext{
* Correspondence: ekeeper@inha.ac.kr

${ }^{1}$ Department of Social and Preventive Medicine, School of Medicine, Inha University, Incheon, Korea

${ }^{2}$ Department of Occupational and Environmental Medicine, School of Medicine, Inha University, 7-206 3rd St. Shinhung Dong, Jung Gu, Incheon, Korea

Full list of author information is available at the end of the article
}

mortality, affecting $3 \%$ of live births and $2.55 \%$ in Europe $[4,5]$. The burden of birth defects in the South East Asian regions remains unknown due to a lack of national-level surveillance mechanism [2]. In Korea, the prevalence of birth defects was $2.86 \%$ [6], and the increase in the prevalence of some defects is becoming a major public health concern.

It has been reported that the cause of $60 \%$ of congenital birth defects is unknown and primary prevention is impossible, and approximately $20 \%$ of congenital cases are caused by genetic disorders [7]. In addition, it has been suggested that multiple factors play an etiologic role in the development of birth defects; the potential risk factors include chemical pollutants, dietary imbalances, ionizing radiation, and infections [8]. Besides, the prevalence rate of birth defects has increasingly been used as an indicator of exposure to several kinds of 
teratogens, particularly pesticides and pharmaceutical substances [9].

In the last few decades, early research investigating the trends of birth defects has shown variation to the temporal changes in the prevalence of birth defects. The prevalence of several birth defects has increased over time, including, for example, heart defects, obstructive genitourinary defects, Down syndrome, and gastroschisis [10-12]. Neurological defects, particularly anencephaly and spina bifida, have shown a significant decrease over time in several areas due to supplementation of food with fortified folic acid, development of prenatal diagnosis and elective termination before 20 weeks of gestation $[1,2,11,13]$. In addition, decreasing trends have also been reported for other birth defects such as club foot and cleft lip with or without cleft palate [11]. Research involving some birth defects, mainly undescended testis and hypospadias, in the petrochemical areas and nonindustrialized areas has concluded that there is a significant difference in their prevalences based on environmental characteristics $[14,15]$. Furthermore, it has been reported that resident area during pregnancy, threatened abortion history, medication history during the first trimester, alcohol consumption, mother's age and weight during pregnancy and parental consanguinity are also related to birth defects [16-18].

Over the past 40 years, Korea has transformed itself into a vibrant capitalist economy with a rapid rate of urbanization, aggravating the environmental degradation. At the same time, it is likely that the pattern of birth defects is changing with time. Despite the fact that the overall prevalence of birth defects in Korea is lower or similar to that of most developed countries, the increase in the prevalence of some categories of birth defects still poses a major public health concern. Although several studies have examined the characteristics of birth defects, few studies have been conducted in Korea. The objectives of this study are to estimate the current prevalence and types of birth defects in Korea and to describe the prevalence of selected birth defects.

\section{Methods}

The study protocol was approved by the institutional review board (IRB) of the University of Inha School of Medicine before the start of the study. We have participated in the health monitoring program for newborn babies supported by the Ministry of Environment, Korea. The Ministry of Environment asked the Korea National Health Insurance Corporation (NHIC) to allow us access to the insurance claims database. This study used the insurance claims database for 2009-2010 and estimated the prevalence of birth defects using data from seven metropolitan areas (Seoul, Pusan, Daegu, Incheon, Gwangju, Daejeon, and Ulsan). The need for consent was waived by the IRB, because we only use NHIC database without private individual information. NHIC collects information on the insurance society, type of medical care institution, episodes of hospital admission, birthday, day of first visit, days of visits, diseases code, total expenses, and other individual characteristics. Target population for analysis comprised 403,250 infants aged less than one year. Analysis of the medical insurance claims database of birth defects diagnosed during the first year after birth was performed to obtain information on the study subjects. Data on the same birth defect in the same patient from various organizations were assembled and reviewed. The possibility of multiple occurrences of birth defects in the same patient was considered. An infant or a fetus with more than one anomaly was counted once only based on the primary diagnosis. A total of 46,679 infants were selected for referring to birth defects code or subcode. When these results were further refined based on the reconfirmation of diagnoses, rule out diagnoses, disease name and exclusion of inappropriate cases, 35,697 study subjects from patients born from 2009 to 2010 were selected for final analysis. Birth defects were classified according to International Classification of Diseases, Tenth version (ICD-10). Cases of minor anomalies (Q32.0, Q67.0Q67.8, Q68.0, Q68.3-Q68.5, Q76.0, Q76.5, Q82.5, Q83.3, Q84.5, Q95.0, Q95.1) treated as outpatients were excluded from further analysis. The birth defects code from Q00 to Q99 included 27,645 cases, and analysis of 69 major birth defects, which were used in some European Surveillance of Congenital Anomalies (EUROCAT) studies, reduced the number of subjects to 22,111 .

In addition, the prevalence of birth defects for 20092010 was compared with that of a similar study conducted 16 years previously [19]. In this study, 601,376 infants aged under one year were covered by medical insurance in 1993 and 601,459 in 1994. The ICD-9 codes were used to classify birth defects and codes 740-759.9 were investigated. Data from pharmacies, dental clinics, and oriental medical clinics were excluded due to unreliability of diagnosis and 44,305 study subjects were selected for final analysis. To identify the matching codes of birth defects between 1993-1994 and 2009-2010, ICD-10 was converted to ICD-9, using ICD10Data.com, and common defects were selected. According to this procedure, 26 different categories and subcategories of birth defects were selected.

Birth defect prevalence was calculated by dividing the numerator (registered cases of congenital anomalies) by the relevant denominator (the number of infants below one year of age among medical insurance dependents). The prevalence was expressed as the number of cases per 10,000 live births. The Poisson distribution was used to calculate $95 \%$ confidence interval of birth defects 
prevalence. Statistical analyses were performed using Stata version 11.2, and alpha was set at $p<0.05$.

\section{Results}

Birth defects in 2009-2010

The number of live births in the study areas was 403,250 from 2009-2010, with 196,532 in 2009 and 206,718 in 2010. Table 1 shows the prevalence rate of birth defects found in this study, reporting the prevalence rate of 548.3 per 10,000 births (95\% CI: 541.1-555.6). The gender-wise prevalences of birth defects according to the involved organ or system are shown in Table 2.

\section{Birth defects of the central nervous system}

Four cases of anencephaly (0.05 per 10,000; $95 \%$ CI: $0.03-0.3), 311$ cases of spina bifida (7.7 per 10,000; $95 \%$ CI: 6.9-8.6), 28 cases of encephalocele (0.7 per 10,000; 95 \% CI: 0.5-1.0), 122 cases of microcephaly (3.0 per 10,000; 95 \% CI: 2.5-3.6), 53 cases of holoprosencephaly (1.3 per 10,000; $95 \%$ CI: $1.0-1.7$ ), and 133 cases of congenital hydrocephalus (2.8 per 10,000; 95 \% CI: $2.3-3.4$ ) were registered with associated prevalence rates at birth of 8.1 per 10,000 births (95\% CI: 7.2-9.0) for males and 7.6 per 10,000 births ( $95 \%$ CI: 6.7-8.5) for females.

\section{Birth defects of eye, ear, face and neck}

It was found that 140 cases of the defects were recorded in boys (3.5 per 10,000; 95 \% CI: 2.9-4.1) and 101 cases in girls (2.5 per 10,000; $95 \%$ CI: 2.0-3.0). The most common were microtia (2.9 per 10,000; $95 \%$ CI: $2.4-$ $3.4)$, congenital cataract (1.4 per 10,000; $95 \%$ CI: $1.1-$ 1.8 ), and congenital glaucoma (0.7 per 10,000; $95 \% \mathrm{CI}$ : $0.5-1.0)$. One girl had anophthalmos, while five cases of absence of iris (two in males and three in females), 18 cases of microphthalmos (eight in males and 10 in females), and 16 cases of congenital absence of auricle (nine in males and seven in females) were reported.

\section{Birth defects of the cardiovascular system}

Congenital anomalies of the circulatory system affected more infants born ( $44.2 \%$ of all birth defects) in the study area than any other type of birth defects: 4,761 in boys (118.1 per 10,000; $95 \%$ CI: 114.7-121.5) and 5,007 in girls (124.2 per 10,000; $95 \%$ CI: $120.8-127.7)$. The three most common types of heart malformations were atrial septal defect (117.9 per 10,000; $95 \%$ CI: $114.6-$ $121.3)$, ventricular septal defect (62.9 per 10,$000 ; 95 \%$ CI: 60.5-65.4), and patent ductus arteriosus (40.1 per 10,000; 95 \% CI: 38.2-42.1).

\section{Birth defects of lip and palate}

The study found 403 cases of cleft palate without cleft lip (10 per 10,000; $95 \%$ CI: 9.0-11.0), 164 in boys (4.1 per 10,000; $95 \%$ CI: $3.5-4.7)$ and 239 in girls (5.9 per
10,000; 95 \% CI: 5.2-6.7); 330 with cleft lip with or without cleft palate (8.2 per 10,000; 95 \% CI: 7.3-9.1), 198 in boys (4.9 per 10,000; $95 \%$ CI: 4.3-5.6) and 132 in girls (3.3 per 10,000;95 \% CI: 2.7-3.9); and 17 with choanal atresia (0.4 per 10,000; $95 \%$ CI: $0.2-0.7), 11$ in boys $(0.3$ per 10,000; $95 \% \mathrm{CI}: 0.1-0.5)$ and six in girls $(0.1$ per 10,000; 95 \% CI: 0.05-0.3).

\section{Birth defects of the digestive system}

It was found that 536 cases of the defects were diagnosed in boys (13.3 per 10,000; $95 \%$ CI: 12.2-14.5) and 458 in girls (11.4 per 10,000; $95 \%$ CI: 10.3-12.4). Hirschsprung's disease (7.7 per 10,000; 95 \% CI: $6.9-$ 8.6), anorectal atresia/stenosis (6.0 per 10,000; $95 \% \mathrm{CI}$ : 5.2-6.8), and small intestine atresia/stenosis (3.5 per 10,000; 95 \% CI: 3.0-4.2) were mainly reported.

\section{Birth defects of the urogenital system}

There were 5,250 reported cases of congenital anomalies of the urogenital system, resulting in the prevalence of 104.6 per 10,000 in boys (95\% CI: 101.4-107.8) and 25.6 in girls (95 \% CI: 24.1-27.2). The most common anomalies were obstructive genitourinary defect (46.1 per 10,000; 95 \% CI: 44.1-48.3), congenital hydronephrosis (33.0 per 10,000; $95 \%$ CI: 31.2-34.8), undescended testis (29.1 per 10,000; $95 \%$ CI: 27.5-30.8), and hypospadias (9.9 per 10,000; $95 \%$ CI: $27.5-30.8$ ).

\section{Birth defects of limbs and musculoskeletal system}

Structural limb anomalies include dysplasia, reduction defects and duplication defects with supernumerary limb elements. Of the 4,261 cases (1,903 males and 2,358 females), congenital hip dislocation (61.3 per 10,000; $95 \%$ CI: $58.9-63.8)$, polydactyly (15.4 per 10,000; $95 \%$ CI: 14.2-16.6), craniosynostosis (9.6 per 10,000; $95 \%$ CI: $8.7-10.6)$, and syndactyly (9.1 per 10,000; $95 \%$ CI: $8.1-$ 10.0) were most prevalent.

\section{Chromosomal anomalies}

102 boys ( 2.5 per 10,000; $95 \%$ CI: 2.1-3.1) and 87 girls (2.2 per 10,000; 95 \% CI: 1.7-2.7) had Down syndrome, the most commonly reported congenital autosomal anomaly. Three boys and four girls had Turner syndrome, while seven boys had Kleinfelter syndrome.

\section{Prevalence of birth defects in 1993-1994 and 2009-2010} In 1993-1994, the overall prevalence of birth defects per 10,000 infants less than one year was 368.3 (95\% CI: 364.9-371.8), and cardiovascular anomalies were the most common defects followed by musculoskeletal and gastrointestinal anomalies [19]. Table 3 shows the prevalence $(95 \% \mathrm{CI})$ for the selected birth defects based on the ranking of decreased prevalence according to percentage change in 2009-2010 with respect to 1993- 
Table 1 Prevalence of birth defects in Korea, 2009-2010

\begin{tabular}{|c|c|c|c|c|}
\hline Birth Defects (ICD-10) & $\begin{array}{l}\text { Number of } \\
\text { cases }\end{array}$ & $\begin{array}{l}\text { Proportion (\%) in } \\
\text { birth defect }\end{array}$ & $\begin{array}{l}\text { Prevalence per } \\
10,000\end{array}$ & $95 \% \mathrm{Cl}$ \\
\hline Nervous system (Q00-07) & 631 & 2.85 & 15.6 & 14.5 to 16.9 \\
\hline Anencephaly (Q00-002) & 4 & 0.02 & 0.05 & 0.03 to 0.3 \\
\hline Spina bifida (Q05.0-05.9) & 311 & 1.4 & 7.7 & 6.9 to 8.6 \\
\hline Encephalocele (Q01.0-01.9) & 28 & 0.1 & 0.7 & 0.5 to 1.0 \\
\hline Microcephaly (Q02) & 122 & 0.6 & 3.0 & 2.5 to 3.6 \\
\hline Holoprosencephaly (Q04.0-04.2) & 53 & 0.2 & 1.3 & 1.0 to 1.7 \\
\hline Congenital hydrocephalus (Q03.0-03.9) & 113 & 0.5 & 2.8 & 2.3 to 3.4 \\
\hline Eye, ear, face and neck (Q10-18) & 241 & 1.1 & 6.0 & 5.2 to 6.8 \\
\hline Anophthalmos (Q11.0-11.1) & 1 & 0.005 & 0.02 & 0.001 to 0.1 \\
\hline Microphthalmos (Q11.2) & 18 & 0.1 & 0.4 & 0.3 to 0.7 \\
\hline Congenital cataract (Q12.0) & 57 & 0.3 & 1.4 & 1.1 to 1.8 \\
\hline Absence of iris (Q13.1) & 5 & 0.02 & 0.05 & 0.04 to 0.3 \\
\hline Congenital glaucoma (Q15.0) & 29 & 0.1 & 0.7 & 0.5 to 1.0 \\
\hline Congenital absence of auricle (Q16.0) & 16 & 0.07 & 0.4 & 0.2 to 0.6 \\
\hline Microtia (Q17.2) & 115 & 0.5 & 2.9 & 2.4 to 3.4 \\
\hline Circulatory system (Q20-28) & 9768 & 44.2 & 242.2 & 237.5 to 247.1 \\
\hline Common atrial trunk (Q20.0) & 10 & 0.05 & 0.25 & 0.1 to 0.5 \\
\hline Translocation of great vessels (Q20.3) & 72 & 0.3 & 1.8 & 1.4 to 2.2 \\
\hline Single ventricle (Q20.4) & 45 & 0.2 & 1.1 & 0.8 to 1.5 \\
\hline Tetralogy of fallot (Q21.3) & 167 & 0.8 & 4.1 & 3.5 to 4.8 \\
\hline Ventricular septal defect (Q21.0) & 2536 & 11.5 & 62.9 & 60.5 to 65.4 \\
\hline Atrial septal defect (Q21.1) & 4756 & 21.5 & 117.9 & 114.6 to 121.3 \\
\hline Pulmonary valve atresia/stenosis (Q22.0-22.1) & 332 & 1.5 & 8.2 & 7.4 to 9.2 \\
\hline Tricuspid atresia/stenosis (Q22.4) & 8 & 0.04 & 0.2 & 0.1 to 0.4 \\
\hline Ebstein's anomaly (Q22.5) & 25 & 0.1 & 0.6 & 0.4 to 0.9 \\
\hline Hypoplastic left heart syndrome (Q23.4) & 10 & 0.05 & 0.25 & 0.1 to 0.5 \\
\hline Patent ductus arteriosus $(\mathrm{Q} 25.0) c^{\mathrm{a}}$ & 1617 & 7.3 & 40.1 & 38.2 to 42.1 \\
\hline Coarctation of aorta (Q25.1) & 112 & 0.5 & 2.8 & 2.3 to 3.3 \\
\hline Aortic valve atresia/stenosis (Q23.0) & 37 & 0.2 & 0.9 & 0.6 to 1.3 \\
\hline Total anomalous pulmonary venous connection (Q26.2) & 41 & 0.2 & 1.0 & 0.7 to 1.4 \\
\hline Respiratory system (Q30-34) & 750 & 3.4 & 18.6 & 17.3 to 20.0 \\
\hline Choanal atresia (Q30.0) & 17 & 0.08 & 0.4 & 0.2 to 0.7 \\
\hline Cleft lip with or without cleft palate (Q36.0-37.9) & 330 & 1.49 & 8.2 & 7.3 to 9.1 \\
\hline Cleft palate without cleft lip (Q35.1-35.9 & 403 & 1.8 & 10.0 & 9.0 to 11.0 \\
\hline Digestive system (Q38-45) & 994 & 4.5 & 24.7 & 23.1 to 26.2 \\
\hline Oesophagus atresia with or without fistula (Q39-39.1) & 66 & 0.3 & 1.6 & 1.3 to 2.1 \\
\hline Anorectal atresia/stenosis (Q42.0-42.3) & 241 & 1.1 & 6.0 & 5.2 to 6.8 \\
\hline Small intestine atresia/stenosis (Q41.0-41.9) & 142 & 0.6 & 3.5 & 3.0 to 4.2 \\
\hline Duodenal atresia /stenosis (Q41) & 56 & 0.3 & 1.4 & 1.0 to 1.8 \\
\hline Other small intestine atresia/stenosis (Q41.1-41.9) & 86 & 0.4 & 2.1 & 1.7 to 2.6 \\
\hline Hirschsprung's disease (Q43.1) & 311 & 1.4 & 7.7 & 6.9 to 8.6 \\
\hline Atresia of bile ducts (Q44.2) & 86 & 0.4 & 2.1 & 1.7 to 2.6 \\
\hline Annular pancreas (Q45.1) & 6 & 0.03 & 0.1 & 0.05 to 0.3 \\
\hline
\end{tabular}


Table 1 Prevalence of birth defects in Korea, 2009-2010 (Continued)

\begin{tabular}{|c|c|c|c|c|}
\hline Genital organs (Q50-56) & 1631 & 7.4 & 40.4 & 38.5 to 42.5 \\
\hline Undescended testis $(\mathrm{Q} 53-53.9)^{\mathrm{b}}$ & 1174 & 5.3 & 29.1 & 27.5 to 30.8 \\
\hline Hypospadias (Q54-54.9) & 401 & 1.8 & 9.9 & 9.0 to 11.0 \\
\hline Epispadias (Q64.0) & 0 & 0 & 0 & 0 \\
\hline Indeterminate sex (Q56-56.4) & 56 & 0.3 & 1.4 & 1.0 to 1.8 \\
\hline Urinary system (Q60-64) & 3619 & 16.4 & 89.7 & 86.8 to 92.7 \\
\hline Renal agenesis (Q60.0-60.6) & 112 & 0.5 & 2.8 & 2.3 to 3.3 \\
\hline Extrophy of urinary bladder (Q64.1) & 1 & 0.005 & 0.02 & 0.001 to 0.1 \\
\hline Renal dysplasid (Q61.4) & 36 & 0.2 & 0.9 & 0.6 to 1.2 \\
\hline Cystic kidney (Q61.0-61.9) & 280 & 1.3 & 6.9 & 6.2 to 7.8 \\
\hline Obstructive genitourinary defect (Q62.0-62.8, Q64.3) & 1860 & 8.4 & 46.1 & 44.1 to 48.3 \\
\hline Congenital hydronephrosis (Q62.0) & 1330 & 6.0 & 33.0 & 31.2 to 34.8 \\
\hline Musculoskeletal system (Q65-79) & 4261 & 19.3 & 105.7 & 102.5 to 108.9 \\
\hline Reduction deformity, upper limbs (Q71.0-71.9) & 20 & 0.09 & 0.5 & 0.3 to 0.8 \\
\hline Reduction deformity, lower limbs (Q72,0-72.9) & 42 & 0.2 & 1.0 & 0.8 to 1.4 \\
\hline Total limb reduction defects (Q71.0-71.9, Q72.0-72.9, Q73.0-73.8) & 66 & 0.3 & 1.6 & 1.2 to 2.1 \\
\hline Congenital hip dislocation (Q65.0-65.9) & 2473 & 11.2 & 61.3 & 58.9 to 63.8 \\
\hline Club foot-talipes equinovarus (Q66.0) & 87 & 0.4 & 2.2 & 1.7 to 2.7 \\
\hline Diaphragmatic hernia (Q79.0) & 52 & 0.2 & 1.3 & 1.0 to 1.7 \\
\hline Polydactyly (Q69.0-69.9) & 620 & 2.8 & 15.4 & 14.2 to 16.6 \\
\hline Syndactyly (Q70.0-70.9) & 365 & 1.7 & 9.1 & 8.1 to 10.0 \\
\hline Arthrogrypposis multiplex congenital (Q74.3) & 22 & 0.1 & 0.5 & 0.3 to 0.8 \\
\hline Craniosynostosis (Q75.0) & 387 & 1.8 & 9.6 & 8.7 to 10.6 \\
\hline Jeunes syndrome (Q77.2) & 0 & 0 & 0 & 0 \\
\hline Achondroplasia/Hypochondroplasia (Q77.4) & 27 & 0.1 & 0.7 & 0.4 to 1.0 \\
\hline Omphalocele (Q79.2) & 88 & 0.4 & 2.2 & 1.8 to 2.7 \\
\hline Gastroschisis (Q79.3) & 12 & 0.05 & 0.30 & 0.2 to 0.5 \\
\hline Chromosomal abnormalities (Q90-99) & 216 & 1.0 & 5.4 & 4.7 to 6.1 \\
\hline Trisomy 13 (Q91.4-91.7) & 1 & 0.005 & 0.02 & 0.001 to 0.1 \\
\hline Trisomy 18 (Q91.0-91.3) & 5 & 0.02 & 0.1 & 0.04 to 0.3 \\
\hline Down's syndrome (Q90.0-90.9) & 189 & 0.9 & 4.7 & 4.0 to 5.4 \\
\hline Turner's syndrome (Q96.0-96.9) & 7 & 0.03 & 0.2 & 0.1 to 0.4 \\
\hline Kleinfelter's syndrome (Q98.0-98.4) & 7 & 0.03 & 0.2 & 0.1 to 0.4 \\
\hline Wolff-Hirschron syndrome (Q93.3) & 1 & 0.005 & 0.02 & 0.001 to 0.1 \\
\hline Cri-du-chat syndrome (Q93.4) & 6 & 0.03 & 0.1 & 0.05 to 0.3 \\
\hline Total & 22,111 & 100 & 548.3 & 541.1 to 555.6 \\
\hline
\end{tabular}

Birth weight of less than 2,500 $\mathrm{g}$ was excluded. ${ }^{\mathrm{b}} \mathrm{Gestational}$ age of less than 36 weeks was excluded

1994, while Table 4 summarizes the prevalence based on the ranking of increased prevalence. It is seen that the prevalences of most defects, notably, hypospadias and epispadias, atrial septal defect, undescended testis, spina bifida and ventricular septal defect showed higher prevalences in 2009-2010. Figure 1 shows the pictorial variation to birth defect prevalences in 1993, 1994, 2009, and 2010. The prevalence estimates for anencephaly, anorectal atresia/stenosis, congenital hydrocephalus, cystic kidney, diaphragmatic hernia, encephalocele, Ebstein's anomaly and renal agenesis and renal dysplasia tended to cluster together with occasional outliers. Atrial septal defect, patent ductus arteriosus, hypospadias and epispadias, undescended testis, ventricular septal defect and pulmonary valve atresia/stenosis exhibited considerable variation in prevalence across years, whereas spina bifida and syndactyly consistently appeared to have some of the least varying estimates. 
Table 2 Prevalence of birth defects in boys and girls according to involved organs or system

\begin{tabular}{|c|c|c|c|c|}
\hline \multirow[t]{2}{*}{ System } & \multicolumn{2}{|c|}{ Number of cases } & \multicolumn{2}{|c|}{ Prevalence per 10,000 and $95 \% \mathrm{Cl}$} \\
\hline & Male & Female & Male & Female \\
\hline Nervous system (Q00-07) & 326 & 305 & $8.1(7.2-9.0)$ & $7.6(6.7-8.5)$ \\
\hline Eye, ear, face and neck (Q10-18) & 140 & 101 & $3.5(2.9-4.1)$ & $2.5(2.0-3.0)$ \\
\hline Cardiovascular system (Q20-28) & 4,761 & 5,007 & $118.1(114.7-121.5)$ & $124.2(120.8-127.7)$ \\
\hline Lip and palate (Q30-34) & 373 & 377 & $9.3(8.3-10.2)$ & $9.3(8.4-10.3)$ \\
\hline Digestive system (Q38-45) & 536 & 458 & $13.3(12.2-14.5)$ & $11.4(10.3-12.4)$ \\
\hline Urogenital system (Q50-64) & 4,217 & 1,033 & $104.6(101.4-107.8)$ & $25.6(24.1-27.2)$ \\
\hline Musculoskeletal system (Q65-79) & 1,903 & 2,358 & $47.2(45.1-49.4)$ & $58.5(56.1-60.9)$ \\
\hline Chromosomal anomalies (Q90-99) & 115 & 101 & $2.9(2.4-3.4)$ & $2.0(2.0-3.0)$ \\
\hline Total & 12,371 & 9,740 & $306.8(301.4-312.2)$ & $241.5(236.8-246.4)$ \\
\hline
\end{tabular}

\section{Discussion}

The overall prevalence of birth defects in our study area in 2009-2010 was 548.3 per 10,000, which is higher compared to the rates of Korea published three years previously [6]. In this study, cardiovascular system defects $(242.2$ per 10,000$)$ were by far the most common defects, followed by defects of the urogenital system (130.1 per 10,000), musculoskeletal system (105.7 per $10,000)$, digestive system (24.7 per 10,000$)$, and nervous system (15.6 per 10,000). Prevalence rates for these defects were grossly similar or slightly higher compared to the rates published previously [6, 14], except for atrial septal defects (117.9 per 10,000; $95 \%$ CI: 114.6-121.3), ventricular septal defects (62.9 per 10,000; $95 \%$ CI: 60.5-65.4), congenital hip dislocation (61.3 per 10,000 ; $95 \%$ CI: 58.9-63.8), obstructive genitourinary defect (46.1 per 10,000; $95 \%$ CI: 44.1-48.3), patent ductus arteriosus (40.1 per 10,000; $95 \%$ CI: 38.2-42.1), undescended testis (29.1 per 10,000; $95 \%$ CI: 27.5-30.8), congenital hydronephrosis (33.0 per 10,000; $95 \% \mathrm{CI}$ : 31.2-34.8), hypospadias (9.9 per 10,000; 95 \% CI: $9.0-$ $11.0)$, pulmonary valve atresia/stenosis (8.2 per 10,000 ; 95 \% CI: 7.4-9.2), spina bifida (7.7 per 10,000; $95 \%$ CI: 6.9-8.6), cystic kidney (6.9 per 10,000; 95 \% CI: 6.2-7.8), and anorectal atresia/stenosis $(6.0$ per 10,000; $95 \% \mathrm{CI}$ : 5.2-6.8) for which the study found particularly high overall rates. Kim et al. [6] reported that the prevalence of birth defects was highest in the circulatory system followed by the musculoskeletal, digestive and urinary systems. Some studies reported the highest prevalence rate in the genitourinary system followed by the central nervous and digestive systems [20], while another study presented the order as the musculoskeletal, digestive, and genitourinary systems [21]. The variations to the reported frequencies could be due to the use of variety and subjectivity of classification criteria. In this study, the proportion of birth defects among males (56\%) is higher than in females (44\%). Similarly, Marden et al. [22] reported that the ratio of male to female infants was 58:42.

The elevated prevalence of heart defects including atrial septal defect and ventricular septal defect in the study is probably due to change in diagnostic method: routine use of echocardiography on newborns may have resulted in the identification of large numbers of defects. Progress in clinical management and more frequent prenatal diagnosis may have increased the prevalence of congenital heart defects, as also suggested by Khoshnood [23]. These results indicate the requirement of standardization of diagnostic and registration criteria for congenital heart anomalies. It is also suggested that environmental factors might play an important role in etiology of congenital

Table 3 Prevalence of selected birth defects in 1993-1994 and 2009-2010, ranking of decreased prevalence

\begin{tabular}{llll}
\hline Order & Birth Defects & \multicolumn{2}{l}{ Prevalence per 10,000 live births $(95 \% \mathrm{Cl})$} \\
\cline { 2 - 4 } & & $1993-1994$ & $2009-2010$ \\
\hline 1 & Anencephaly & $3.4(3.1-3.8)$ & $0.05(0.03-0.3)$ \\
3 & Pulmonary valve atresia/ stenosis & $23.1(22.2-24.0)$ & $8.2(7.4-9.2)$ \\
4 & Tetralogy of fallot & $7.3(6.8-7.8)$ & $4.1(3.5-4.8)$ \\
5 & Translocation of great vessels & $2.9(2.6-3.2)$ & $1.8(1.4-2.2)$ \\
6 & Atresia of bile ducts & $2.9(2.6-3.2)$ & $2.1(1.7-2.6)$ \\
7 & Encephalocele & $0.9(0.8-1.1)$ & $0.7(0.5-1.0)$ \\
\hline
\end{tabular}


Table 4 Prevalence of selected birth defects in 1993-1994 and 2009-2010, ranking of increased prevalence

\begin{tabular}{|c|c|c|c|}
\hline \multirow[t]{2}{*}{ Order } & \multirow[t]{2}{*}{ Birth Defects } & \multicolumn{2}{|c|}{ Prevalence per 10,000 live births $(95 \% \mathrm{Cl})$} \\
\hline & & 1993-1994 & 2009-2010 \\
\hline 1 & Hypospadias and epispadias & $0.7(0.5-0.8)$ & $9.9(9.0-11.0)$ \\
\hline 2 & Atrial septal defect & $9.7(9.1-10.3)$ & $117.9(114.6-121.3)$ \\
\hline 3 & Undescended testis & $2.6(2.3-2.9)$ & $29.1(27.5-30.8)$ \\
\hline 4 & Cystic kidney & $0.7(0.5-0.8)$ & $6.9(6.2-7.8)$ \\
\hline 5 & Congenital hip dislocation & $10.2(9.6-10.8)$ & $61.3(58.9-63.8)$ \\
\hline 6 & Microcephaly & $0.5(0.4-0.7)$ & $3.0(2.5-3.6)$ \\
\hline 7 & Renal agenesis and renal dysplasia & $0.6(0.5-0.8)$ & $3.7(3.1-4.3)$ \\
\hline 8 & Patent ductus arteriosus & $7.0(6.6-7.5)$ & $40.1(38.2-42.1)$ \\
\hline 9 & Syndactyly & $2.7(2.4-3.0)$ & $9.1(8.1-10.0)$ \\
\hline 10 & Spina bifida & $2.8(2.5-3.1)$ & $7.7(6.9-8.6)$ \\
\hline 11 & Ventricular septal defect & $34.1(33.1-35.2)$ & $62.9(60.5-65.4)$ \\
\hline 12 & Congenital hydrocephalus & $1.6(1.4-1.8)$ & $2.8(2.3-3.4)$ \\
\hline 13 & Palate without cleft lip & $6.8(6.3-7.3)$ & $10.0(9.0-11.0)$ \\
\hline 14 & Ebstein's anomaly & $0.5(0.4-0.6)$ & $0.6(0.4-0.9)$ \\
\hline 15 & Diaphragmatic hernia & $1.0(0.8-1.2)$ & $1.3(1.0-1.7)$ \\
\hline 16 & Polydactyly & $13.1(12.5-13.8)$ & $15.4(14.2-16.6)$ \\
\hline 17 & Anorectal atresia/stenosis & $5.3(4.9-5.7)$ & $6.0(5.2-6.8)$ \\
\hline 18 & Hirschsprung's disease & $7.4(6.9-7.9)$ & $7.7(6.9-8.6)$ \\
\hline 19 & Oesophagus atresia with or without fistula & $1.6(1.4-1.8)$ & $1.6(1.3-2.1)$ \\
\hline
\end{tabular}

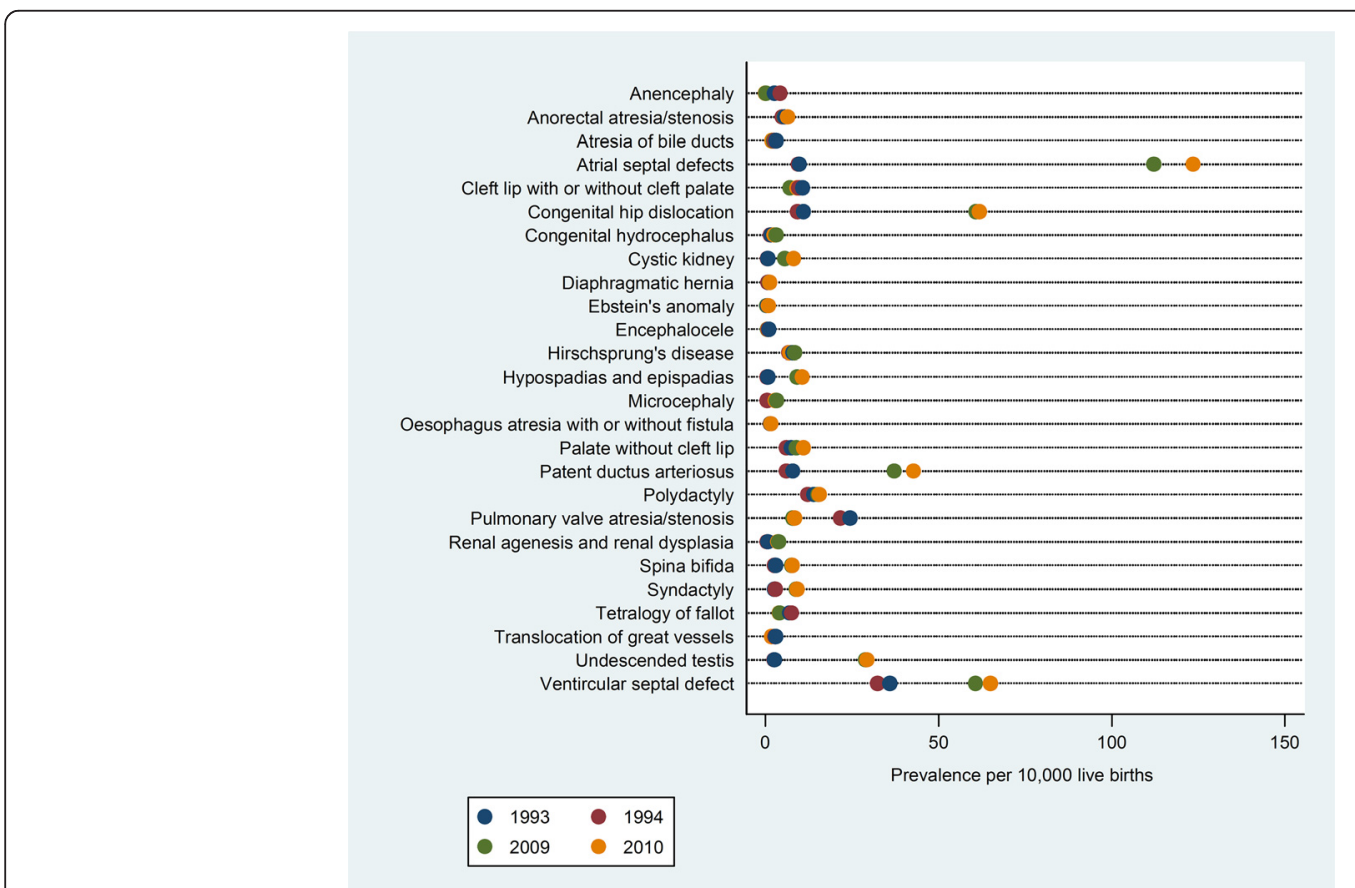

Fig. 1 Prevalence for 26 selected birth defects for 1993, 1994, 2009 and 2010 
heart defects. A meta-analysis study reported that the increased risk of atrial septal defect was related to exposure to $\mathrm{PM}_{10}$ (particulate matter 10) [24]. Likewise, some studies analyzing the association between traffic or the concentration of pollutants such as $\mathrm{PM}_{10}$ and carbon monoxide found that an increased risk of ventricular septal defect was due to maternal exposure to carbon monoxide and patent ductus arteriosus due to exposure to $\mathrm{PM}_{10}$ $[25,26]$.

The birth prevalence of undescended testis varies widely (1.4-31.7). The study found very high rates of undescended testis (29.1 per 10,000) in accordance with data from Canada $(31.7$ per 10,000) but in sharp contrast to the low rate of France $(1.4$ per 10,000) [27]. On the other hand, the birth prevalence for hypospadias (9.9 per $10,000)$ in this study was similar to that reported in France (9.8 per 10,000) [27].

In England, the prevalence of undescended testis increased by more than $60 \%$ between the 1950s and $1980 \mathrm{~s}$, and the reported prevalence of hypospadias is 0.1-0.8 per 10,000 male births [28, 29]. A study conducted in North England found space-time clustering among cases of hypospadias, but not cryptorchidism [30]. The distribution of hypospadias cases may be predicted to exhibit spatial clustering if geographical varying environmental exposures are involved in their etiology. Space-time clustering occurs when an excess number of cases is observed within a small geographical area over a short period of time. In Spain, the frequency of hypospadias was $0.35 \%$ and remained constant at this level for the past few decades, and a decreasing frequency was recorded only after 1996 [31]. The authors suggest that a radical change in the exposure that affected the whole country during that decade is a probable cause of that scenario in Spain. Unexpectedly, this sort of trend was not observed in the prevalence of any other birth defects. A study conducted in China reported an average annual increase in the overall prevalence of hypospadias of 7.34 \% from 1996 to 2008, with geographical variation to increasing trends. The authors suggest that environmental exposure might play a critical role in the development of hypospadias [32]. Previous studies have suggested that the prevalence of undescended testis increased during the past half century in industrialized countries, and the spatial variation to the prevalence at birth has been indicated [30, 33]. Some studies have suggested that spatial and temporal trends of undescended testis and hypospadias might be associated with environmental factors, with minor involvement of genetic characteristics, and are among the most likely causes [33]. A number of animal-based studies have shown that perinatal exposure to exogenous oestrogens and antiandrogens may cause hypospadias, undescended testis, reduced sperm count and testicular cancers in males
[33]. Chemicals such as pesticides, polychlorinated biphenyls, dioxins, naturally occurring plant estrogens, phthalates, bisphenol $\mathrm{A}$ and mycotoxins have been reported to affect reproduction in humans through endocrine-mediated processes [29]. However, a clear effect of an endocrine-induced disruption of chemical on reproductive organs in humans is yet to be established. Some studies found no strong epidemiological evidence to indicate a link between prenatal exposure to estrogen and malformation of male reproductive organs [28]. North and Golding found that a maternal vegetarian diet was a risk factor for hypospadias due to phytoestrogens in this type of diet [34]. Moreover, previous studies reported that the risk of birth defect varies according to the type of occupation [35-38]. A significant link was observed between maternal involvement in agricultural activities and an increased frequency of birth defects in the offspring. Pesticide exposure is likely in agricultural work even though direct handling of chemicals is not reported [36]. Therefore, the use of fertilizers, croppreserving chemicals and use of spray in greenhouses can be major sources of exposure during agricultural activities. An increased risk among sons of mothers who were employed in gardening was also reported [38].

In particular, the prevalence of hypospadias and undescended testis in the study areas showed remarkably higher prevalence rates compared to the study conducted 16 years ago (Table 4). The tendency of increment was also higher than the national prevalence of undescended testis and hypospadias between 2000 and 2005. A study conducted in Korea reported an increased tendency from 5.01 to 17.43 per 10,000 persons for cryptorchidism and from 1.40 to 3.28 per 10,000 persons for hypospadias during that period [14]. Although the comparability of reported rates is poor, there may be an important underlying temporal variation which cannot be properly addressed until ascertainment and diagnostic criteria are standardized.

Hirschprung's disease (7.7 per 10,000), the most common congenital gut motility disorder, is relatively easy to diagnose, thus, the relatively higher prevalence compared to North England (1.63 per 10,000) [39] is probably due to genuinely higher prevalence of this defect in the study areas. Although some studies have indicated that this disease is inherited, environmental factors may be responsible for sporadic cases [40].

With regard to nervous system defects, particularly spina bifida (7.7 per 10,000), the prevalence rate was comparable to that of Japan $(6.2$ per 10,000$)$ but higher than found in the United States (3.8 per 10,000) [27]. The reason for this higher prevalence may be associated with dietary consumption of folate. It has been suggested that folate intake varies between populations, and lack of this nutrient is known to cause such defects [41]. A 
study conducted in Korea reported that fewer women $(10.3 \%)$ take folate in the periconceptional period [42].

The prevalence rate for Down syndrome (4.7 per $10,000)$ was particularly low in the study areas; however, other population-based studies had reported higher than this figure in Finland (31.0 per 10,000), France (27.3 per 10,000), and Japan (10.9 per 10,000) [27]. This syndrome can be diagnosed relatively easily prior to birth. Hence, it is likely that many fetuses with the syndrome might have aborted electively, and this may have contributed to the variable prevalence rates.

The existence of etiological heterogeneity for the birth defects has been described elsewhere in the literature [43]. A number of studies analyzed the association between the environmental and nutritional factors and the prevalence of undescended testis and spina bifida, respectively, and many studies found a significant association. In particular with undescended testis and hypospadias, evidence from experimental biological investigations and epidemiological studies have left little doubt that these defects can be a result of disruption of embryonic and gonadal development during fetal life. As the prevalence rates are higher in the study areas, the etiological impact of adverse environmental factors such as hormone disruptor, might be acting on susceptible genetic background, may be considered for further studies. However in order to obtain a dataset that is as complete as possible, systematic data gathering and surveillance of birth defects must be established in Korea. Registration of defects in elective terminations is very important as many defects are now identified prenatally and exclusion of aborted cases may complicate the identification of environmental factors [44]. Therefore, in attempting to describe the prevalence and spatiotemporal changes of birth defects, establishment of a registry system of birth defects, and environmental surveillance at national and local levels is needed for further study.

However, the results in this study must be interpreted in the context of some limitations. The study cannot avoid the methodological limitation of insurance based data analysis. Diagnostic criteria, coding and the timing for follow-up of outpatients might vary in the hospitals, and further validation of the diagnosis was difficult with the insurance database analysis due to lack of detailed records. For example, some newborns with birth defects might have died before entering the hospital, although the number of such patients should be rare. In addition, ICD-9 codes were used to specify birth defects for years 1993-1994, while ICD-10 was used to classify birth defects for 2009-2010. Two versions of disease classification differ substantially. The change to the tenth revision resulted in more detailed classification, with about 8,000 categories compared with about 5,000 categories in the ninth revision. The relatively large difference of some birth defects reported between 1993-1994 and 20092010 may be due to the switch from ICD-9 to ICD-10. This study used a comparable category of codes for 26 selected defects according to the ninth and tenth revisions. However, there may be an important underlying variation to case ascertainment and diagnostic criteria (inclusion or exclusion of minor cases) which may have given higher reported rates in some birth defects. A study found the comparability ratio of 0.9064 between ICD-10 and ICD-9 while explaining congenital anomalies and chromosomal abnormalities as a cause of death in the United States [45]. Nonetheless, this study is helpful in understanding increased prevalence of some important birth defects in Korea.

\section{Conclusion}

Relatively higher rates of some birth defects were found in the metropolitan areas. The high difference of birth prevalences for septal heart defects and undescended testis are probably due in part to progress in clinical management and more frequent prenatal diagnosis. Environmental exposure might play a critical role in the development of some birth defects. In attempting to describe the prevalence and spatio-temporal variations of birth defects in Korea, establishment of a registry system of birth defects and environmental surveillance are needed.

\section{Abbreviations}

Cl: confidence interval; EUROCAT: European Surveillance of Congenital Anomalies; ICD-10: International Classification of Diseases, Tenth version; NHIC: National Health Insurance Corporation.

\section{Competing interests}

The authors declare that they have no competing interests.

\section{Authors' contributions}

$\mathrm{DL}$ directly participated in the planning, execution, and analysis of the study. MP and JAK performed database clearing and analysis of data. HK

participated in analysis of data. $J L$ participated in the design of the study and prepared this manuscript. JHK and YH conceived of the study, and participated in its design and coordination. All authors read and approved the final manuscript

\section{Acknowledgements}

The authors wish to acknowledge the technical assistance of the National Health Insurance Corporation, Korea.

\section{Funding}

This study was supported by the Ministry of Environment, Republic of Korea.

\section{Author details}

'Department of Social and Preventive Medicine, School of Medicine, Inha University, Incheon, Korea. ${ }^{2}$ Department of Occupational and Environmental Medicine, School of Medicine, Inha University, 7-206 3rd St. Shinhung Dong, Jung Gu, Incheon, Korea. ${ }^{3}$ Department of Integrative Bioscience \& Biotechnology, Sejong University, 209 Neungdong-ro, Gwangjin-gu, Seoul 05006, Korea. ${ }^{4}$ Department of Preventive Medicine, College of Medicine, Seoul National University, Seoul, Korea. 
Received: 8 December 2013 Accepted: 7 March 2016 Published online: 22 March 2016

\section{References}

1. Carmona RH. The global challenges of birth defects and disabilities. Lancet. 2005;366:1142-4

2. WHO. Capacity building for birth defects surveillance in Southeast Asia.: Report of the Regional Workshop on Birth Defects; 2012:1-53.

3. Czeizel AE. The primary prevention of birth defects: Multivitamins of folic acid. Int J Med Sci. 2004;1:50-61.

4. CDC. Infant mortality statistics from the 2008 period linked birth/infant death data set.: National Vital Statistics Report; 2012: 1-27.

5. EUROCAT. The health and care of pregnant women and babies in Europe in 2010.: European Perinatal Health Report; 2013:1-250.

6. Kim MA, Yee NH, Choi JS, Choi JY, Seo K. Prevalence of birth defects in Korean livebirths, 2005-2006. J Korean Med Sci. 2012;27:1233-40.

7. Liu S, Joseph KS, Wen SW. Trends in fetal and infant deaths caused by congenital anomalies. Semin Perinatol. 2002;26:268-76.

8. Lechat MF, Dolk H. Registries of congenital anomalies: EUROCAT. Environ Health Perspect. 1993:101:153-7.

9. Koldjensen T. Congenital malformations, in: Children's health and environment: A review of evidence. A joint report from the European Environment Agency and the WHO Regional Office for Europe. Office for Official Publications of the European communities; 2002:116-126.

10. Chew C, Halliday JL, Riley MM, Penny DJ. Population-based study of antenatal detection of congenital heart disease by ultrasound examination. Ultrasound Obstet Gynecol. 2007;29:619-24.

11. Correa A, Cragan JD, Kucik JE, Alverson CJ, Gilboa SM, Balakrishnan R, Strickland MJ, Duke CW, O'Leary LA, Riehle-Colarusso T, et al. Reporting birth defects surveillance data 1968-2003. Birth Defects Res A Clin Mol Teratol. 2007;79:65-186

12. Cocchi G, Gualdi S, Bower C, Halliday J, Jonsson B, Myrelid A, et al. International trends of Down syndrome 1993-2004: births in relation to maternal age and terminations of pregnancies. Birth Defects Res A Clin Mol Teratol. 2010:88:474-9.

13. Besser LM, Williams LJ, Cragan JD. Interpreting changes in the epidemiology of anencephaly and spina bifida following folic acid fortification of the U.S. grain supply in the setting of long-term trends, Atlanta, Georgia, 1968-2003. Birth Defects Res A Clin Mol Teratol. 2007;79:730-6.

14. Kim SC, Kwon SK, Hong YP. Trends in the incidence of cryptorchidism and hypospadias of registry-based data in Korea: a comparison between industrialized areas of petrochemical estates and a non-industrialized area. Asian J Androl. 2011;13:715-8.

15. Fernandez MF, Olmos B, Granada A, López-Espinosa MJ, Molina-Molina JM, Fernandez JM, Cruz M, Olea-Serrano F, Olea N. Human exposure to endocrine-disrupting chemicals and prenatal risk factors for Cryptorchidism and Hypospadias: A Nested case-control study. Environ Health Perspect. 2007:115:8-14

16. Watkins ML, Rasmussen SA, Honein MA, Botto LD, Moore CA. Maternal obesity and risk for birth defects. Pediatrics. 2003;111:1152-8.

17. Stoll C, Alembik Y, Roth MP, Dott B. Parental consanguinity as a cause for increased incidence of birth defects in a study of 238,942 consecutive births. Ann Genet. 1999;42:133-9.

18. Lee KT, Yang EJ, Lim SY, Pyon JK, Mun GH, Bang SI, Oh KS. Association of congenital microtia with environmental risk factors in South Korea. Int J Pediatr Otorhinolaryngol. 2012;76:357-61.

19. Jung SC, Kim SS, Yoon KS, Lee JS. Prevalence of congenital malformations and genetic diseases in Korea. J Hum Genet. 1999:44:30-4.

20. Kang BH, Lee JG, Chung KH, Yang JB, Kim DY, Rhee YE, Noh HT. Incidence of congenital anomalies and diagnosis of congenital anomalies by antenatal ultrasonography. Korean J Obstet Gynecol. 2004;47:2070-6.

21. Hong S, Lee B, Choi D, Yang Y. The clinical epidemiologic study of congenital anomalies in the newborn infants. Korean J Obstet Gynecol. 1986;29:686-91.

22. Marden PM, Smith DW, McDonald MJ. Congenital anomalies in the newborn infant, including minor variations: a study of 4,412 babies by surface examination for anomalies and buccal smear for sex chromatin. J Pediatr. 1964;64:357-71

23. Khoshnood B, De Vigan C, Vodovar V, Goujard J, Lhomme A, Bonnet D, Goffinet F. Trends in prenatal diagnosis, pregnancy termination, and perinatal mortality of newborns with congenital heart disease in France, 1983-2000: a population-based evaluation. Pediatrics. 2005;115(1):95-101.

24. Vrijheid M, Martinez D, Manzanares S, Dadvand P, Schembari A, Rankin J, Nieuwenhuijsen M. Ambient air pollution and risk of congenital anomalies: A systematic review and meta-analysis. Environ Health Perspect. 2010;119: 598-606.

25. Dadvand P, Rankin J, Rushton S, Pless-Mulloli T. Association between maternal exposure to ambient air pollution and congenital heart disease: A register-based spatiotemporal analysis. Am J Epidemiol. 2011;173:171-82.

26. Strickland MJ, Klein M, Correa A, Reller MD, Mahle WT, Riehle-Colarusso TJ, Botto LD, Flanders WD, Mulholland JA, Siffel C, et al. Ambient air pollution and cardiovascular malformations in Atlanta, Georgia, 1986-2003. Am J Epidemiol. 2009;169:1004-14.

27. ICBDSR. Annual report 2011 with data for 2009. Annual Report; 2011:1-320.

28. Storgaard $\mathrm{L}$, Bonde JP, Olsen J. Male reproductive disorders in humans and prenatal indicators of estrogen exposure: a review of published epidemiological studies. Reprod Toxicol. 2006;21:4-15.

29. Toppari J, Kaleva M, Virtanen HE. Trends in the incidence of cryptorchidism and hypospadias, and methodological limitations of registry-based data. Hum Reprod Update. 2001;7:282-6.

30. McNally RJQ, Abdullah NA, Pearce MS, Parker L, Wilkinson JR. Space-time clustering of cryptorchidism and hypospadias. Epidemiology. 2007:18:183-4.

31. Martínez-Frías ML, Prieto D, Prieto L, Bermejo E, Rodriguez-Pinilla E, Cuevas L. Secular decreasing trend of the frequency of hypospadias among newborn male infants in Spain. Birth Defects Res A Clin Mo Teratol. 2004:70:75-81.

32. Dai L, Zhu J, Liang J, Wang YP, Wang H, Mao M. Birth defects surveillance in China. World J Pediatr. 2011:7(4):302-10.

33. Skakkebaek NE, Rajpert-De Meyts E, Main KM. Testicular dysgenesis syndrome: an increasingly common development disorder with environmental aspects. Hum Reprod. 2001;16:972-8.

34. North K, Golding J. A maternal vegetarian diet in pregnancy is associated with hypospadias. BJU Int. 2000:85:107-13.

35. Pierik FH, Burdorf A, Deddens JA, Juttmann RE, Weber RFA. Maternal and paternal risk factors for cryptorchidism and hypospadias: a case-control study in newborn boys. Environ Health Perspect. 2004;112:1470-576.

36. Garcia-Rodriguez J, Garcia-Martin M, Nogueras- Ocana M, Luna-del-Castillo JD, Garcia ME, Olea N, Lardelli-Claret P. Exposure to pesticides and cryptorchidism: geographical evidence of a possible association. Environ Health Perspect. 1996;104:1090-5.

37. Garcia AM, Fletcher T, Benavides FG, Orts E. Parental agricultural work and selected congenital malformations. Am J Epidemiol. 1999;149:64-74.

38. Weidner IS, Moller H, Jensen TK, Skakkebak NE. Cryptorchidism and hypospadias in sons of gardeners and farmers. Environ Health Perspect. 1998;106:793-6

39. Best KE, Glinianaia SV, Bythell M, Rankin J. Hirschsprung's disease in the North of England:Prevalence, associated anomalies, and survival. Birth Defects Res A Clin Mol Teratol. 2012;94(6):477-80.

40. Hofstra RM, Osinga J, Buys CH. Mutations in Hirschsprung disease: when does a mutation contribute to the phenotype. Eur J Hum Genet. 1997:5(4):180-5.

41. Honein MA, Paulozzi $\amalg$, Mathews TJ, Erickson JD, Wong LY. Impact of folic acid fortification of the US food supply on the occurrence of neural tube defects. JAMA. 2001;258(23):2981-6

42. Kim MH, Han JY, Cho YJ, Ahn HK, Kim JO, Ryu HM, Kim MY, Yang JH, NavaOcampo AA. Factors associated with a positive intake of folic acid in the periconceptional period among Korean women. Public Health Nutr. 2009; 12(4):468-71.

43. Li Z, Ren A, Zhang L, Guo Z, Li Z. A population-based case-control study of risk factors for neural tube defects in four high-prevalence areas of Shanxi province, China. Paediatr Perinat Epidemiol. 2006;20:43-53.

44. Limb CJ, Holmes LB. Anencephaly: changes in prenatal detection and birth status, 1972 through 1990. Am J Obstet Gynecol. 1994;170(5 Pt1):1333-8.

45. CDC. Comparability of cause of death between ICD-9 and ICD-10: Preliminary estimates.: National Vital Statistics Report; 2001: 1-32. 